\title{
OBSERVATIONS BY IMMUNOFLUORESCENCE MICROSCOPY AND ELECTRON MICROSCOPY ON THE CYTOPATHOGENICITY OF NAEGLERIA FOWLERI IN MOUSE EMBRYO-CELL CULTURES
}

\author{
T. BROWN \\ Department of Bacteriology, University of Aberdeen, Foresterhill, Aberdeen AB9 2ZD \\ Plates XXIV-XXXI
}

It has been suggested (Brown, 1978, 1979) that Naegleria fowleri may destroy cultured mouse-embryo (ME) cells by a phagocytosis- like mechanism alone, although the evidence for this is not conclusive. ME cells in contact with vigorously motile trophozoites were seen by phase-contrast microscopy to suffer gradual loss of cytoplasm (Brown, 1978), but observations at high magnification were hampered by peripheral image halos that obscured fine detail and the process of engulfment itself could not be discerned. Further studies of the cytopathogenicity of $N$. fowleri were carried out, therefore, by immunofluorescence and electron-microscopic techniques designed to show clearly how amoebae attack and destroy mammalian cells in vitro.

\section{MATERIALS AND METHODS}

Cultures. Trophozoites of Naegleria fowleri strain HB-1 were maintained at $37^{\circ} \mathrm{C}$ in Fulton's medium A (Fulton, 1970) and harvested for inoculation of cell cultures as described previously (Brown, 1978).

Secondary ME-cell cultures and associated media were prepared according to Brown (1978). ME-cell coverslip cultures for immunofluorescence studies were established in Leighton tubes. For electron microscopy, the technique of Persijn and Scherft (1965) was used whereby ME-cell monolayers were cultured on $25 \times 17-\mathrm{mm}$ thin mica slips (Mica and Micanite Supplies Ltd, London) in $30-\mathrm{mm}$ plastic petri dishes. The freshly seeded dishes were incubated for 2 days at $37^{\circ} \mathrm{C}$ in a humidified atmosphere of $5 \%(\mathrm{v} / \mathrm{v}) \mathrm{CO}_{2}$ in air, then changed to maintenance medium (MM).

Preparation of $M E$-cell antiserum. Two-day-old secondary ME-cell monolayers in 20-oz (568 $\mathrm{ml})$ screw-capped glass bottles were trypsinised and the cells washed by centrifugation at $800 \mathrm{~g}$

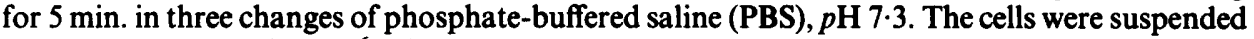
at a concentration of $1 \times 10^{6} / \mathrm{ml}$ in $0.1 \%(\mathrm{v} / \mathrm{v})$ formol saline and the suspension was divided into two equal parts. One part was sonicated for $2 \mathrm{~min}$. in a Mullard 50-watt ultrasonic disintegrator (Medical and Scientific Equipment Ltd, Crawley, Sussex); the other was centrifuged at $800 \mathrm{~g}$ for $5 \mathrm{~min}$. and the deposit resuspended in the sonicated preparation. The formolised antigen, containing whole cells and sub-cellular components, was stored at $4^{\circ} \mathrm{C}$ in small volumes for up to 18 days until required for inoculation of animals.

New Zealand White rabbits were given intravenous inoculations of ME-cell antigen according to a schedule similar to that described previously for the preparation of amoeba-specific

Received 21 Dec. 1978; accepted 28 Jan. 1979. 
antiserum (Brown, 1979). The resulting ME-cell antiserum was stored in 2-ml volumes at $-20^{\circ} \mathrm{C}$.

Immunofluorescence studies. Leighton-tube cultures of ME cells were inoculated with $5 \times 10^{4}$ amoebae and incubated at $37^{\circ} \mathrm{C}$ for up to $24 \mathrm{~h}$ when cytopathic effect (CPE) was almost complete. Coverslips were removed at intervals, rinsed in PBS, placed in cold $\left(4^{\circ} \mathrm{C}\right)$ acetone for $15 \mathrm{~min}$. and air-dried. The fixed preparations were stained, by the indirect technique, with ME-cell antiserum diluted 1 in 32 in PBS and a 1 in 10 dilution of fluorescein-labelled sheep anti-rabbit globulin (Wellcome Reagents Ltd, Beckenham). The coverslips were mounted in Polarfluor B (Polaron Equipment Ltd, Watford) and examined by blue-light fluorescence microscopy. Uninoculated ME-cell cultures were processed in the same way. Pre-inoculation (non-immune) rabbit serum and non-conjugated anti-rabbit globulin (blocking reagent) were incorporated as controls in all tests.

Cytochalasin B (Aldrich Chemical Co., Ltd, Gillingham, Dorset), prepared and stored as a stock solution according to Brown (1979), was incorporated in cell-culture medium at a concentration of $10 \mu \mathrm{g} / \mathrm{ml}$ in similar immunofluorescence experiments.

Electron microscopy. Mica-slip cultures of ME cells were inoculated with $5 \times 10^{3}$ or $1 \times 10^{5}$ amoebae and incubated at $37^{\circ} \mathrm{C}$ in an atmosphere of $5 \%(\mathrm{v} / \mathrm{v}) \mathrm{CO}_{2}$ in air for up to $24 \mathrm{~h}$. As CPE progressed, mica slips were removed gently from the petri dishes, drained, immersed in $2.5 \%$ glutaraldehyde in approximately $0.09 \mathrm{M}$ phosphate buffer, $p \mathrm{H} 7 \cdot 2$, for $2 \mathrm{~h}$ at $4{ }^{\circ} \mathrm{C}$, rinsed in three changes of $0.25 \mathrm{M}$ sucrose in phosphate buffer and placed in $1 \%(\mathrm{w} / \mathrm{v})$ osmium tetroxide solution for $1 \mathrm{~h}$ at $20^{\circ} \mathrm{C}$. Control (uninoculated) ME-cell monolayers were fixed likewise. After rinsing in distilled water, the slips were examined by low-power microscopy, and areas of particular interest were circumscribed by means of a diamond object marker (Leitz Instruments Co., Luton) fitted to the microscope nosepiece. The fixed cells were dehydrated by transfer through a graded series of ethanol solutions and impregnated with epoxy resin by immersion in successively increasing concentrations of Araldite (Ciba-Geigy UK, Ltd, Cambridge) in 1,2-epoxypropane, followed by three changes in Araldite alone. The slips were removed from the Araldite and laid, cells uppermost, on velin tissue. Gelatin capsules, filled with fresh Araldite, were inverted quickly over the previously marked areas and the Araldite was heat-polymerised. The mica was peeled from the hardened blocks and the gelatin was dissolved in hot water. Thin sections were cut from the trimmed blocks with a diamond knife, stained with a saturated solution of uranyl acetate followed by lead citrate (Reynolds, 1963), and examined in a Philips EM 301 electron microscope at $50 \mathrm{kV}$ with a $50-\mu \mathrm{m}$ thin foil objective aperture.

\section{RESULTS}

\section{Immunofluorescence microscopy}

ME cells in control and in naegleria-infected cultures treated with ME-cell antiserum showed a fine granular fluorescence that was largely confined to the cytoplasm (figs. 1-5). Fluorescent nuclear granules were seen occasionally, but it was not clear whether these were nucleoli or superimposed cytoplasmic organelles. Fluorescence was not seen in similar preparations treated with non-immune rabbit serum, and blocking tests confirmed the specificity of the fluorescein-labelled anti-rabbit globulin.

In cultures harvested $15 \mathrm{~min}$. after inoculation with Naegleria trophozoites, amoebae scattered amongst the brightly-fluorescing ME cells were identified by their relatively small size and uniform dull bronze or olive colour (fig. 2). One hour after inoculation, when individual mammalian cells were beginning to show signs of damage, ME-cell antigen in the form of fluorescing granules was detected in the cytoplasm of some trophozoites (fig. 3). These granules 
increased in number as CPE progressed and by $3 \mathrm{~h}$ they were observed in almost all trophozoites (fig. 4). Twenty-four $h$ after inoculation, the ME cells were almost entirely destroyed, leaving a few scattered nuclei surrounded by cytoplasmic remnants, while the amoebae correspondingly contained numerous discrete granules of mammalian-cell antigen (fig. 5).

In the presence of cytochalasin B, naegleria-induced CPE was inhibited and the ME cells showed only characteristic drug-associated morphological changes (fig. 6). The trophozoites were devoid of granular ME-cell antigen, even after incubation for $24 \mathrm{~h}$, contrasting greatly with amoebae in cytochalasin B-free cultures (compare fig. 5).

\section{Electron microscopy}

The appearance of ME cells in thin sections prepared from control monolayers is shown in fig. 7. Trophozoites in sections of naegleria-infected ME-cell cultures were easily distinguished by their morphology and fine structure (fig. 8). Notable identifying features included the characteristic amoeba nucleus with its large nucleolus, and the distinctive mitochondria containing coarse, granular cristae. The organisms were often adjacent to ME cells and showed signs of vigorous phagocytic activity (figs. 9-13). Amoebae were clearly seen in the act of ingesting fragments of mammalian-cell cytoplasm which were detached from intact ME cells by a remarkable pincer-like action of two pseudopodia. This ingestion process, illustrated most strikingly in figs. 9 and 10, was detected within $90 \mathrm{~min}$. of inoculation of the cell cultures, although accurate interpretation of electron-microscope findings was not always easy. As indicated by comparison of figs. 9 and 11, the appearance of complete ingestion of ME-cell cytoplasm by some trophozoites (fig. 12) may have been artefactual, depending on the section level observed. A similar explanation probably accounted for the rare occurrence of apparently intracellular amoebae (figs. 13 and 14). ME-cell microtubules were often prominent in cytoplasm that was constricted by closing pseudopodia, and a region of ribosome-free cytoplasm containing a network of fine filaments approximately $6 \mathrm{~nm}$ in diameter was observed consistently at the tips of the pseudopodia themselves (figs. 9, 10 and 12).

There was no evidence for disruption of ME-cell cytoplasm before or during engulfment by the amoebae (fig. 10). Occasional margination of nuclear chromatin and some cell rounding and cytoplasmic shrinkage were apparent 22-24 $\mathrm{h}$ after inoculation of the cultures, but the fine structure of the mammalian cells seemed otherwise quite normal (fig. 15). Filamentous structures interspersed between the cells may have been fragmented remains of ME-cell cytoplasm left by the trophozoites, or possibly sectioned points of attachment of the cells to the mica surface. The cytoplasmic membranes of the mammalian cells generally remained intact, despite the obvious feeding activity of amoebae as denoted by increased numbers of trophozoite food vacuoles with time (compare figs. 8 and 15). The contents of the vacuoles were identified as fragments of ME-cell cytoplasm by reference to immunofluorescence studies 
(fig. 15) and, if recently ingested, by the mammalian-type morphology of the mitochondria. Other fragments were degraded, showed increased electron density, and became reduced to little more than membranous whorls.

\section{Discussion}

According to current opinion, $N$. fowleri probably destroys mammalian cells by a combination of two mechanisms - by secreting enzyme-like cytotoxic substances and by direct phagocytic attack (Maitra et al., 1974, 1976; Visvesvara and Callaway, 1974; Cursons and Brown, 1978). The evidence for naegleria-associated cytotoxic activity is largely circumstantial, being based on the histological appearance of human brain tissue from cases of primary amoebic meningoencephalitis (Butt, Baro and Knorr, 1968; Duma et al., 1969, 1971; Chang, 1974), and on electron-microscope studies of host damage caused by $N$. fowleri in experimentally infected mice or cell cultures (Martinez et al., 1971, 1973; Maitra et al., 1974, 1976; Visvesvara and Callaway, 1974). Supernatant medium from in-vitro cultures of amoebae has been shown to contain a cytotoxic factor (Chang, 1971, 1974) or phospholipases (Cursons, Brown and Keys, 1978), but the role of these substances in the pathogenicity of $N$. fowleri remains uncertain. Brown (1978) was unable to demonstrate the secretion of cytotoxins by trophozoites in mammalian-cell cultures.

The present observations, with those reported earlier (Brown, 1978, 1979), provide firm evidence that trophozoites of $N$. fowleri destroy cultured ME cells by a phagocytosis-like mechanism alone. Immunofluorescence studies showed that the development of CPE in amoeba-infected cell cultures coincided with the rapid accumulation of fluorescing granules of mammaliancell antigen within trophozoites. The granules, presumably enclosed in food vacuoles, clearly represented engulfed fragments of ME-cell cytoplasm. Their early appearance and increase in number with time suggested that trophozoites began ingesting host-cell material soon after they were inoculated into the cultures and continued this activity until CPE was complete. Significantly, the absence of naegleria-induced CPE in cultures containing cytochalasin $\mathrm{B}$, an inhibitor of phagocytosis by $N$. fowleri (Brown, 1979), was associated with the failure of amoebae to engulf ME-cell cytoplasm as shown by their total lack of granular fluorescence.

Light microscope observations of naegleria cytopathogenicity in vitro (Brown, 1978) suggested that amoebae attack ME cells directly rather than by first inducing cell lysis and then feeding on the resulting debris. The present electron-microscope findings support this view. Trophozoites clearly acquired host-cell material by pinching portions of cytoplasm from intact ME cells by means of prominent pseudopodia similar to those seen previously by light microscopy (Brown, 1978). The cytoplasmic shrinkage characteristic of naegleria-induced CPE in ME-cell cultures (Brown, 1978) was undoubtedly due to the constant nibbling of cytoplasm by the organisms as they wandered from one mammalian cell to another. Indeed, an apt description of this activity 

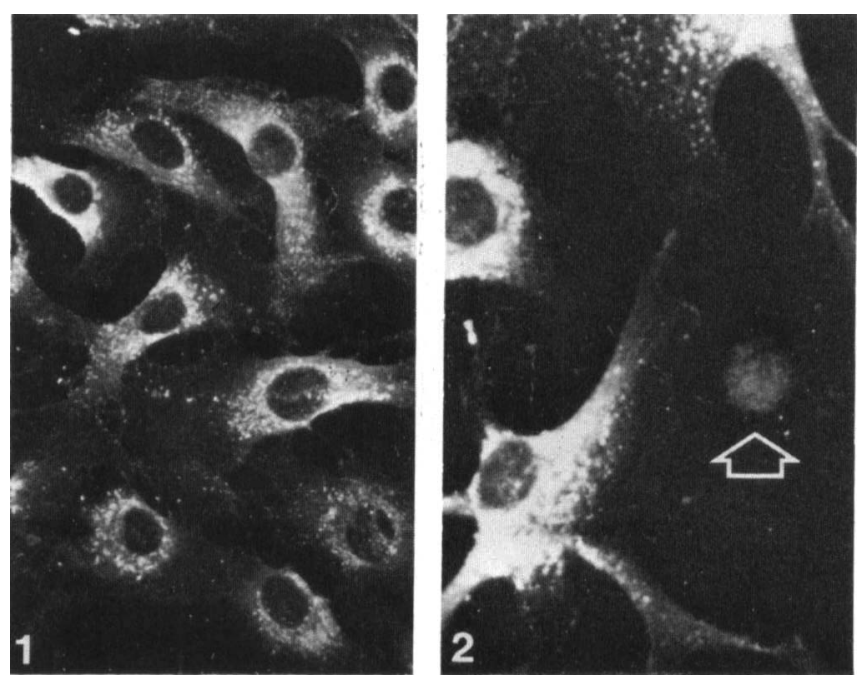

FIG. 1.-Normal, uninoculated mouse-embryo (ME) cells. Indirect immunofluorescence (IF) with ME-cell antiserum. $\times 330$.

FIG. 2.-ME-cell culture $15 \mathrm{~min}$. after inoculation with Naegleria fowleri trophozoites. Arrow indicates a single amoeba showing faint homogeneous autofluorescence. IF. $\times 540$.
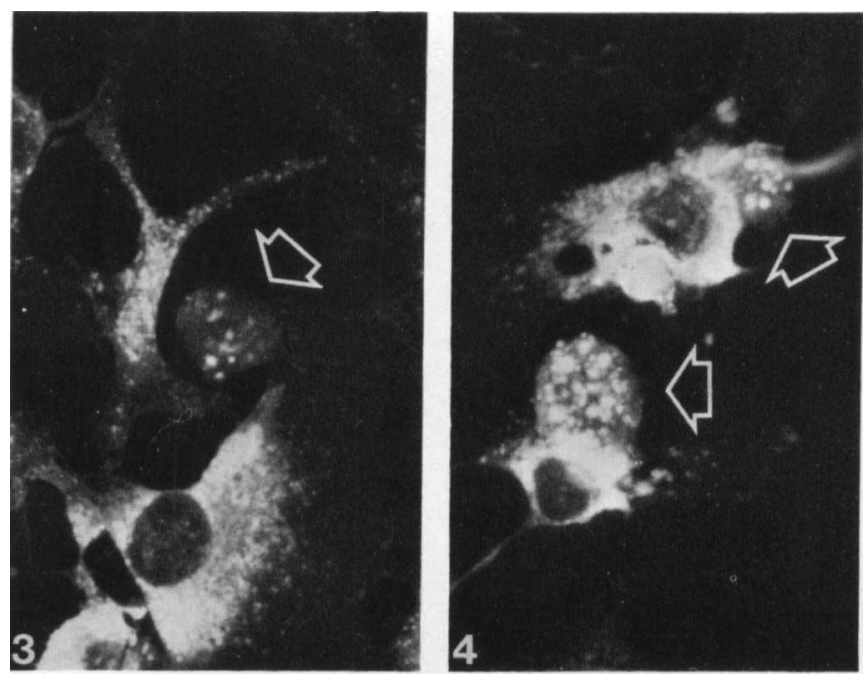

FIG. 3.-ME-cell culture inoculated with $N$. fowleri, $(1 \mathrm{~h})$ showing trophozoite (arrow) with fluorescing cytoplasmic granules adjacent to a damaged ME cell. IF. $\times 540$.

FIG. 4.-ME-cell culture inoculated with $N$. fowleri $(3 \mathrm{~h})$. Amoebae now possess numerous cytoplasmic granules (arrows) and the monolayer shows gross cytopathic effect. IF. $\times 540$. 


\section{CytOPATHOGENICITY OF NAEGLERIA FOWLERI}

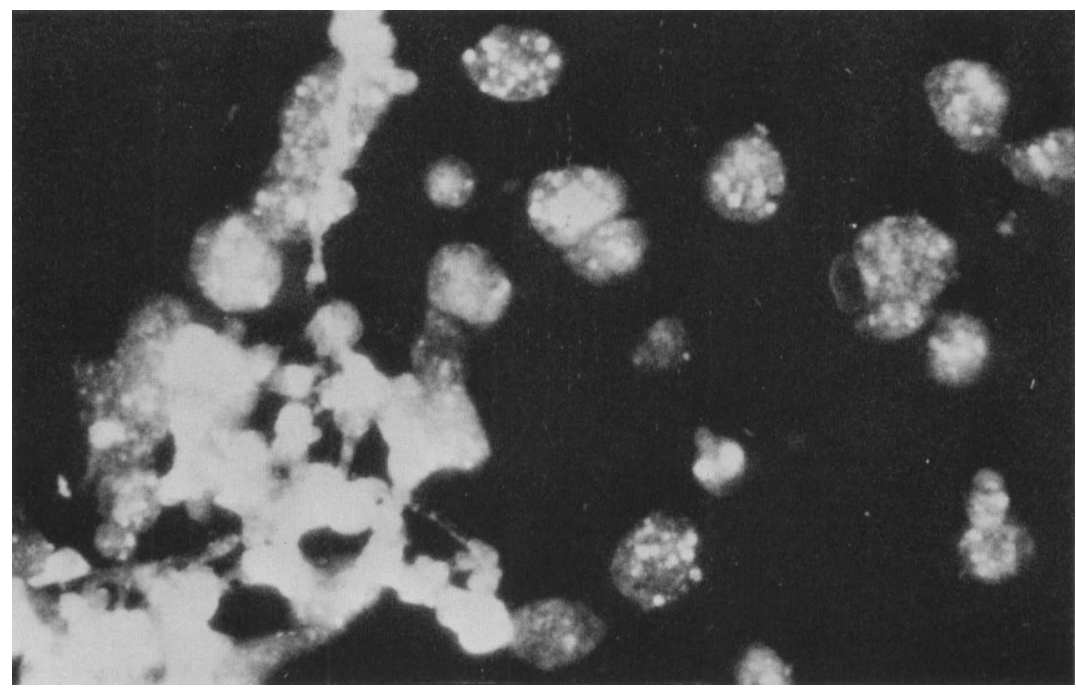

FIG. 5.-ME-cell culture inoculated with $N$. fowleri $(24 \mathrm{~h})$. The monolayer is completely destroyed and almost all trophozoites contain fluorescing granules of ME-cell antigen. IF. $\times 540$.

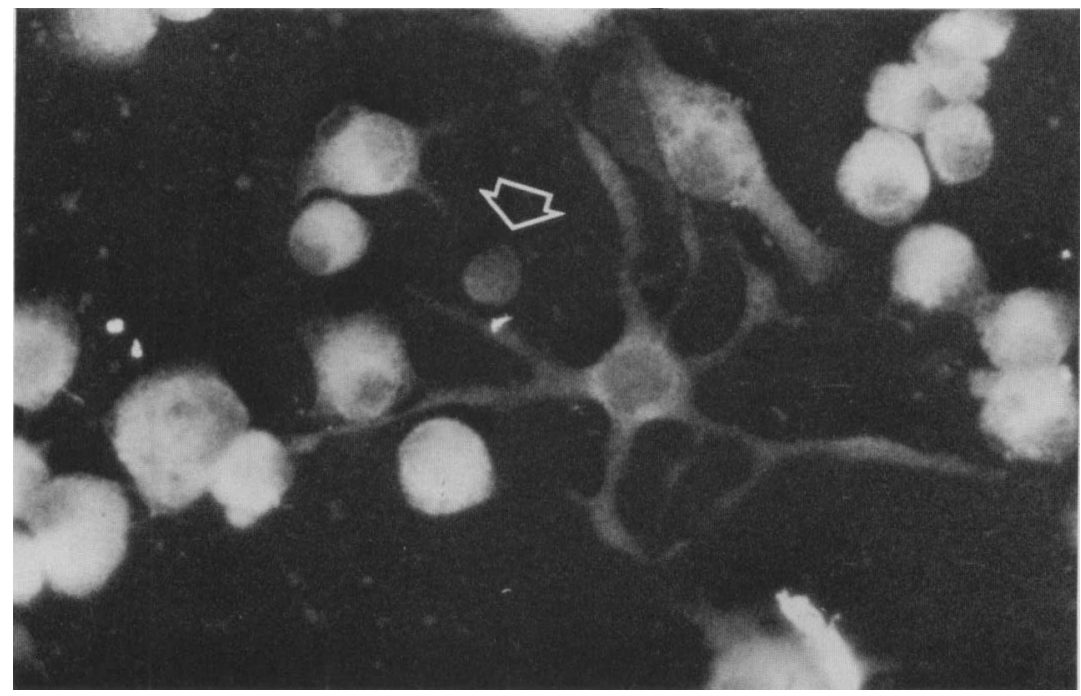

Fig. 6.-ME-cell culture $24 \mathrm{~h}$ after inoculation with $N$. fowleri in the presence of cytochalasin B. The mammalian cells show only drug-induced morphological changes and the trophozoite indicated (arrow) contains no cytoplasmic granules (compare fig. 5) IF. $\times 540$. 


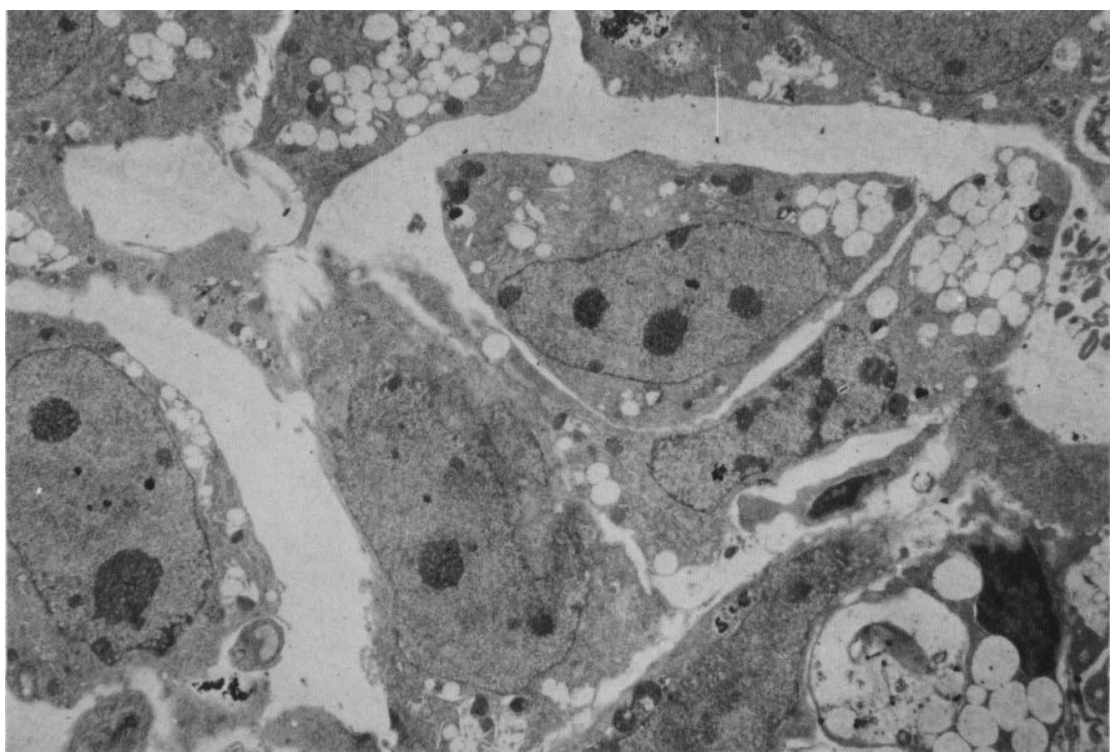

FIG. 7.- Transverse thin section through normal ME-cell monolayer showing the morphology and arrangement of individual cells. Electron micrograph $(\mathrm{EM}) . \times 3020$.

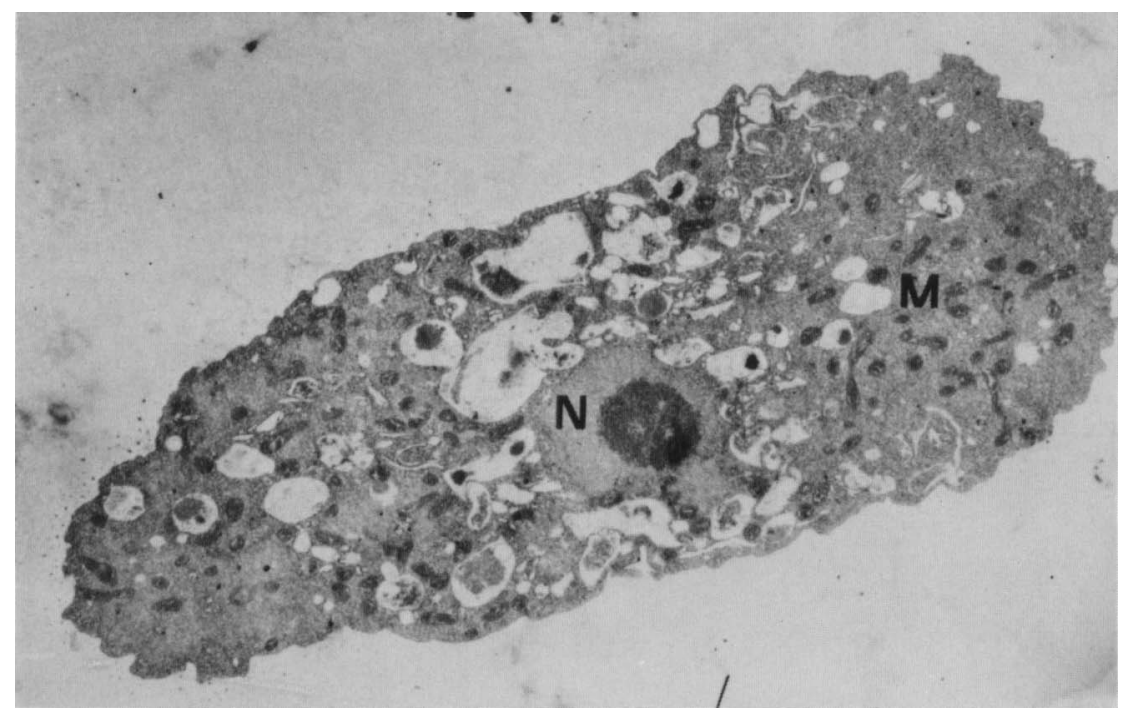

Fig. 8.-N. fowleri trophozoite from ME-cell culture inoculated $2.5 \mathrm{~h}$ previously. Note the distinctive amoeba nucleus $(\mathrm{N})$ and mitochondria $(\mathrm{M}) . \mathrm{EM} . \times 5300$. 
CYTOPATHOGENICITY OF NAEGLERIA FOWLERI

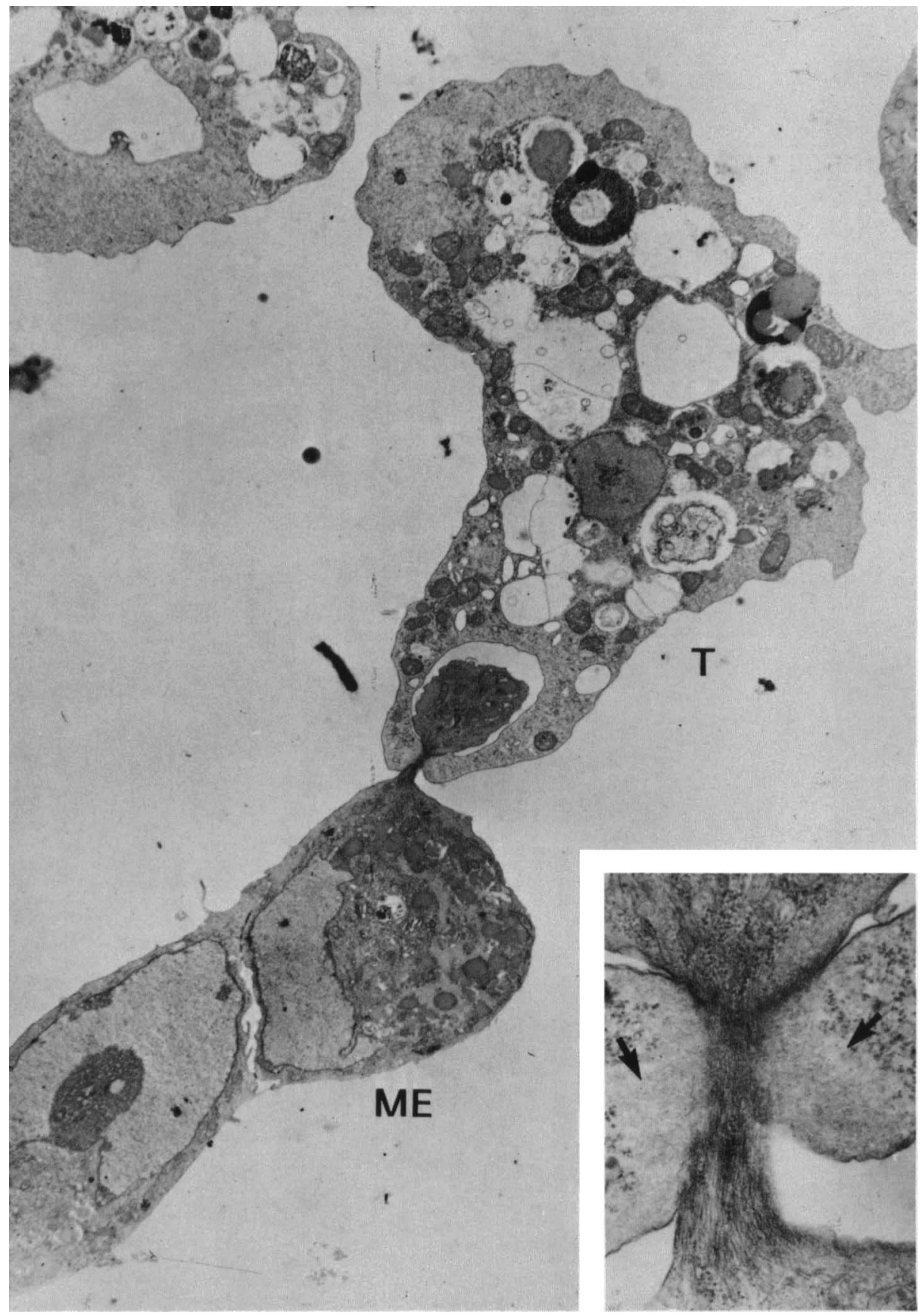

FIG. 9. $-N$. fowleri trophozoite (T) in the process of engulfing a fragment of ME-cell (ME) cytoplasm ( $22 \mathrm{~h}$ after inoculation). EM. $\times 4800$. Inset: the tips of the pseudopodia at higher magnification $(\times 32800)$ showing microfilament-like structures within the ribosome-free cytoplasm (arrows). The constricted ME-cell cytoplasm between the pseudopodia contains prominent microtubules. 


\section{CYtopathogenicity OF NAEGLERIA FOWLERI}

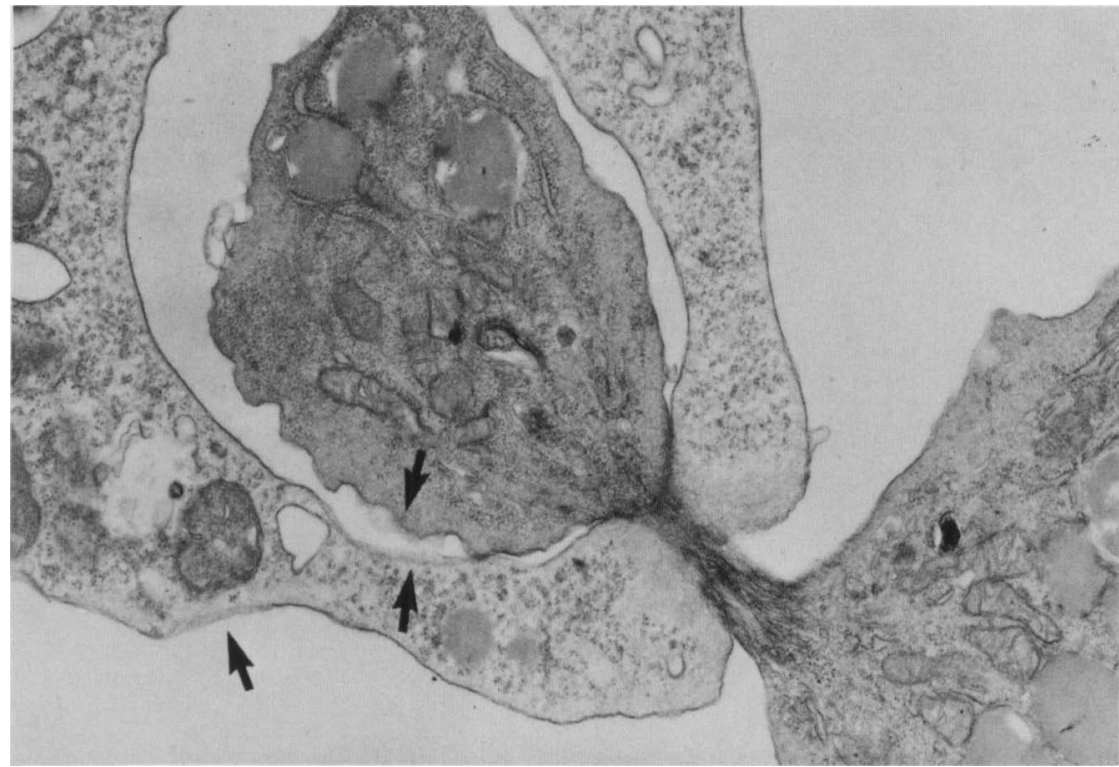

FIG. 10.-The thin section illustrated in fig. 9 at higher magnification. The engulfed portion of ME-cell cytoplasm is intact and shows no signs of cytotoxic damage. The localised diffuse regions (arrows) of the ME-cell and amoeba cytoplasmic membranes are probably due to oblique sectioning at these points. EM. $\times 16800$.

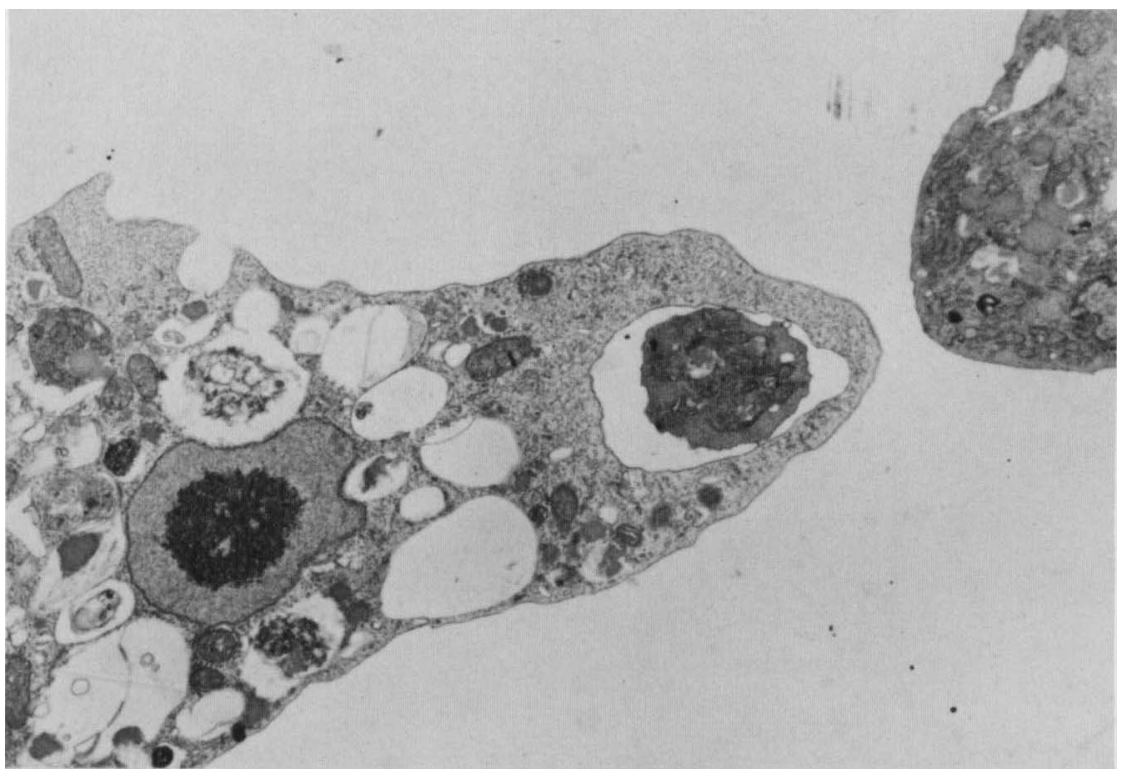

FIG. 11.-Thin section parallel to that of the same preparation illustrated in fig. 9. At this level, the tips of the trophozoite pseudopodia have fused over the ME-cell cytoplasmic constriction which now lies out of the plane of section-hence the appearance of complete engulfment. EM. $\times 6050$. 


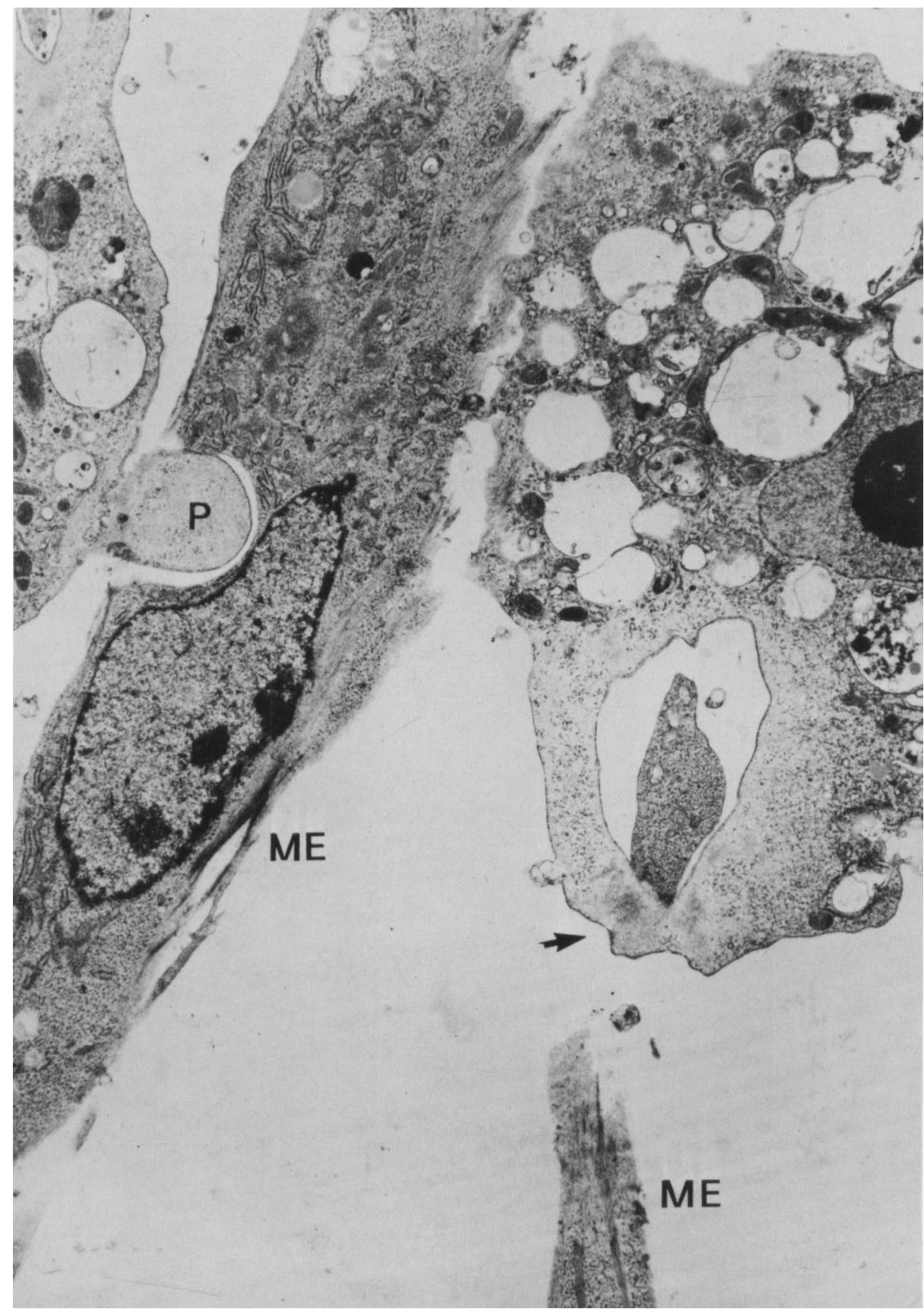

FIG. 12.-ME-cell culture $1.5 \mathrm{~h}$ after inoculation with $N$. fowleri. The pseudopodium (P) of the amoeba on the left has distorted, but has not penetrated the adjacent ME cell; the cell membrane close to the tip of the pseudopodium is intact. The other trophozoite (right) is ingesting a fragment of ME-cell cytoplasm. This may still be attached to the rest of the mammalian cell out of the plane of section (compare figs. 9 and 11). Microfilament-like structures are present near the tips of the fused pseudopodia (arrow). EM. $\times 6900$. 


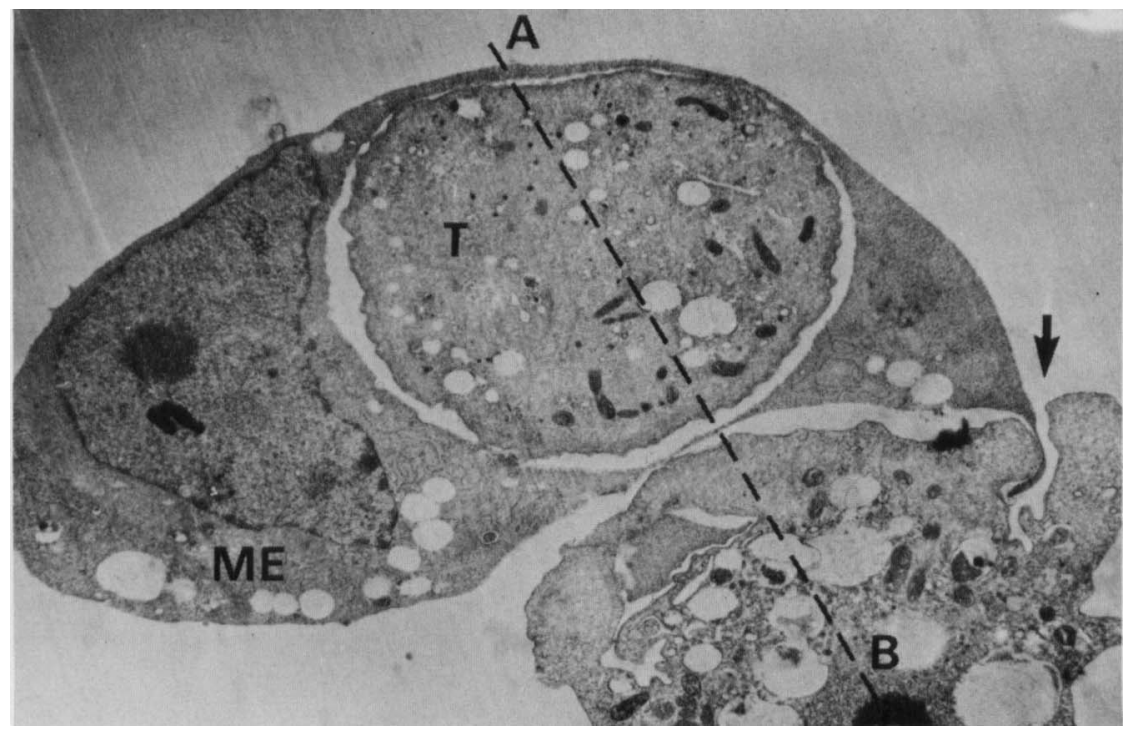

FIG. 13. - Thin section of ME-cell culture $2.5 \mathrm{~h}$ after inoculation with $N$. fowleri, apparently showing an intracellular trophozoite $(T)$. It is not clear whether this is a separate organism or merely part of the amoeba (lower right) that is ingesting a fragment of ME-cell cytoplasm (arrow). A diagramatic interpretation of this section through the plane A-B is given in fig. 14. EM. $\times 5500$.

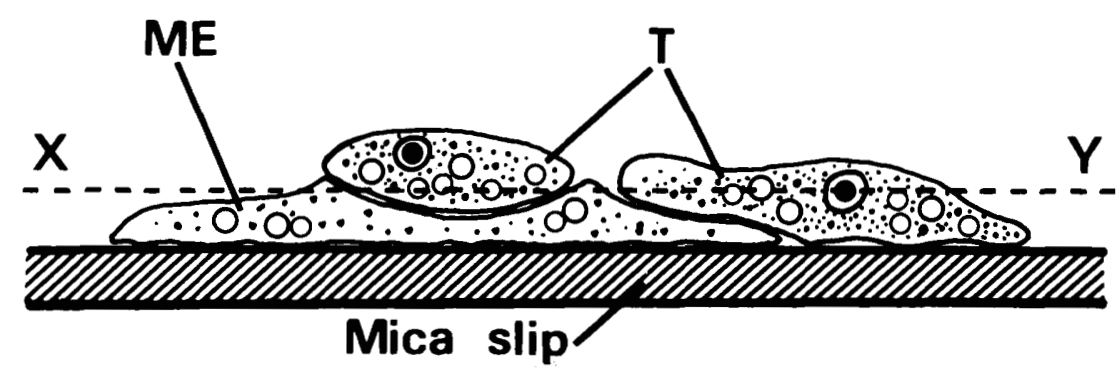

FIG. 14. - Diagram illustrating the possible relationship, at the time of fixation, between the amoebae and the ME cell shown in fig. 13. The preparation seen in the electron micrograph could represent a transverse thin section through the plane $X-Y$; i.e., the appearance of an intracellular amoeba may be a section-induced artefact. 


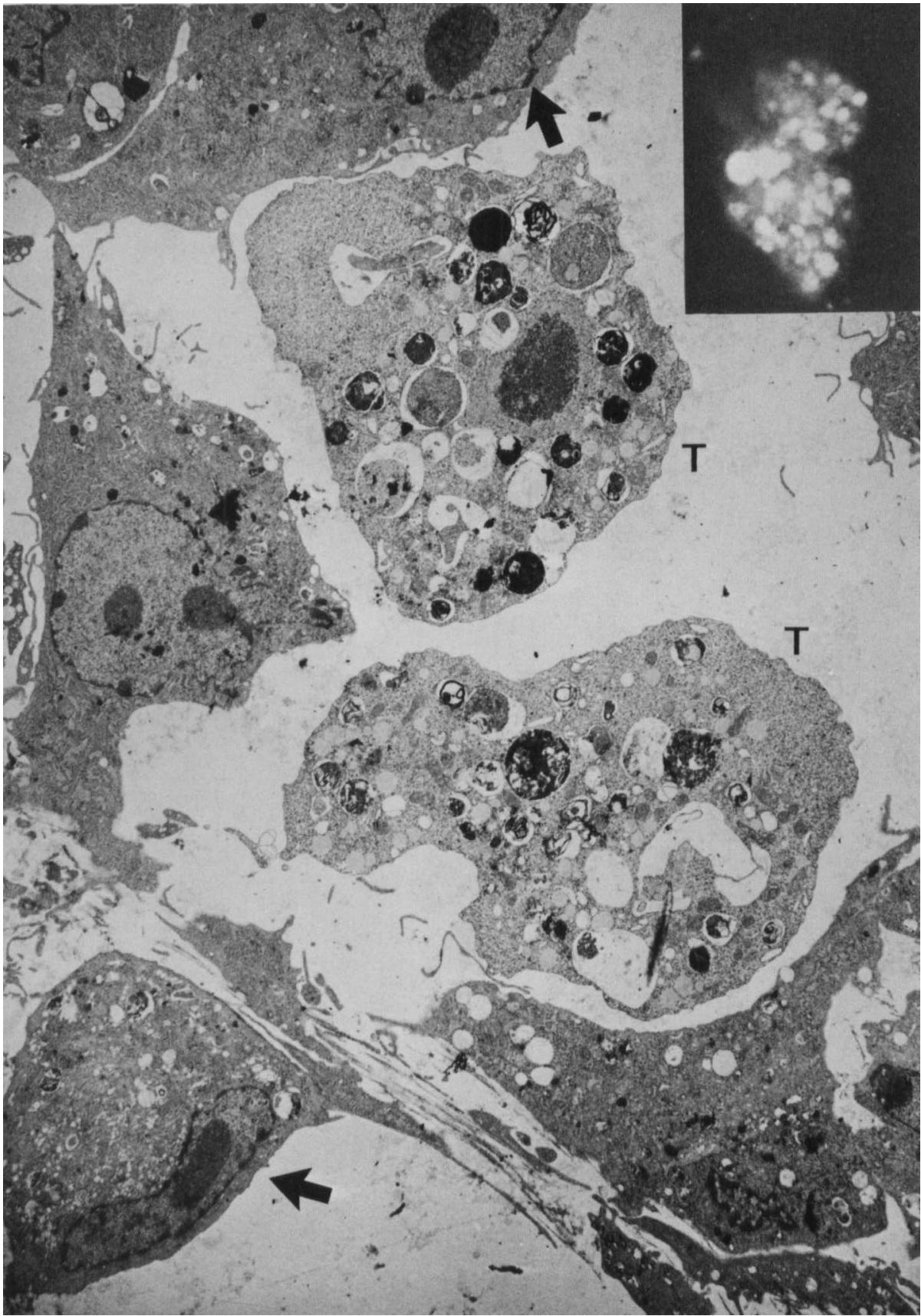

Fig. 15.-Thin section of ME-cell culture inoculated with $N$. fowleri $(24 \mathrm{~h})$. Some ME cells show slight margination of nuclear chromatin (arrows). The amoebae (T) now possess numerous food vacuoles containing host-cell material of varying electron density (compare fig. 8). EM. $\times 3370$.

Inset: trophozoite from similar culture stained by indirect immunofluorescence with ME-cell antiserum. The fluorescing cytoplasmic granules correspond to the food vacuoles seen by electron microscopy. IF. $\times 820$. 
might be "trogocytosis" (Greek: trogo - to nibble), rather than "phagocytosis" which implies the engulfment of whole particles! Certainly, the phenomenon was entirely consistent with Culbertson's (1971) description of the "nibbling, piecemeal fashion" by which pathogenic amoebae ingested erythocytes in vivo.

The continuous, piecemeal engulfment of ME-cell cytoplasm was further suggested by the presence of numerous trophozoite food vacuoles containing cytoplasmic fragments in various stages of degradation, particularly in preparations harvested when CPE was well advanced. Visvesvara and Callaway (1974) reported similar findings, but they also described the frequent location of amoebae within mammalian cells, an observation that may have reflected their use of electron-microscope specimens prepared from scraped and centrifuged cultures. In the present investigation, inoculated ME-cell cultures were fixed and embedded in situ without disturbance of the close association between amoebae and mammalian cells, and the organisms seen in thin sections were almost invariably extracellular. The rare appearance of an intracellular amoeba was considered to be an artefact caused by the plane of section passing horizontally through a trophozoite attached to the depressed surface of a mammalian cell. This interpretation is in accordance with earlier conclusions regarding "intracellular" amoebae seen during light microscope studies of naegleria cytopathogenicity (Brown, 1978).

The suggestion of Cursons et al. (1978), that amoebae initially render host cells susceptible to phagocytic attack by secreting enzymes, is not supported by present findings. Apart from gradual loss of cytoplasm, ME cells adjacent to amoebae generally appeared quite normal and showed no obvious signs of cytotoxic damage. Slight margination of nuclear chromatin, possibly reflecting imminent cell death (Bessis, 1970), was seen occasionally in cultures showing advanced CPE, but the fine structure of the cells remained otherwise intact. The ability of trophozoites to detach portions of cytoplasm from apparently healthy mammalian cells invites speculation on the significance of the microfilament-like networks seen at the tips of ingesting pseudopodia. Visvesvara and Callaway (1974) and Lastovica (1976) also observed microfilament bundles in the cytoplasm of $N$. fowleri, and similar structures have been found in other phagocytic cells including Entamoeba histolytica (Griffin and Juniper, 1971; Westphal, Michel and Mühlpfordt, 1972), mouse peritoneal macrophages (Allison, Davies and de Petris, 1971; Axline and Reaven, 1972; Reaven and Axline, 1973), and polymorphonuclear leucocytes (Stossel, $1974 a, b$ ). Indeed, microfilaments have been identified in many cell types and are believed to be actin polymers that interact with myosin to form a contractile system similar to that found in muscle cells (Pollard and Weihing, 1974). The isolation of a protein complex with actomyosin-like properties from $N$. gruberi (Lastovica and Dingle, 1971) and of actin and myosin from Acanthamoeba castellanii (Weihing and Korn, 1971; Pollard and Korn, $1973 a, b$; Pollard, Stafford and Porter, 1978) provides compelling evidence that such a force-generating system exists in protozoan cells also (Wagner, 1978). Biochemical characterisation of pseudopodial microfilaments was beyond the scope of the present 
investigation, but they were of similar diameter to actin filaments (Pollard and Weihing, 1974) and seemed to be associated with increased trophozoite activity, being found only in pseudopodia that were in the process of engulfing ME-cell cytoplasm. The resulting constriction of mammalian-cell cytoplasm certainly indicated that considerable force was applied by the closing pseudopodia. Coincidentally, cytochalasin B was shown to inhibit the cytopathogenicity of Naegleria, apparently by preventing phagocytosis (Brown, 1979). As cytochalasin B is thought to interfere with cellular motile processes by reacting with contractile microfilaments (Wessels et al., 1971; Hartwig and Stossel, 1976; Plagemann, Graff and Wohlhueter, 1977), the detection of similar structures within trophozoite pseudopodia offers a tangible explanation for the drug's suppressive effect.

There is little doubt that $N$. fowleri exhibits phagocytosis in vivo as well as in cell cultures, but the importance of this activity in the pathogenesis of animal disease is not clear (Martinez et al., 1971, 1973; Maitra et al., 1974, 1976; Visvesvara and Callaway, 1974). Some features of host-cell damage have been ascribed to the action of cytolytic substances released by amoebae, notably the appearance of a clear halo around trophozoites in brain tissue (Maitra et al., 1974, 1976; Visvesvara and Callaway, 1974). Carter (1972) has noted that $N$. fowleri resembles $E$. histolytica in terms of invasiveness and ability to cause tissue necrosis, and E. histolytica has also been reported to kill and lyse mammalian cells on contact (Jarumilinta and Kradolfer, 1964). According to Eaton, Meerovitch and Costerton $(1969,1970)$, the surface of the organism is pitted with cup-shaped lysosomes, complete with a trigger mechanism, that discharge cytolytic enzymes when stimulated by contact with a susceptible host cell, but this hypothesis is open to criticism (Griffin and Juniper, 1971; Griffin, 1972; Newton, 1972). Interestingly, Schuster (1963) found organelles almost identical to E. histolytica "surface lysosomes" (Eaton et al., 1969, 1970) in the non-pathogenic amoeba, $N$. gruberi, and identified them merely as systolic contractile vacuoles. Nevertheless, a search was made during the present study for similar structures in $N$. fowleri trophozoites. Numerous clear vacuoles were seen throughout the cytoplasm, some lying near the plasma membrane, but there was no evidence that they possessed a lysosome-like function or were associated in any way with cytopathogenicity. Visvesvara and Callaway (1974) likewise failed to detect "surface lysosomes' in $N$. fowleri. Indeed, the concept of extracellular cytolysis by this organism may be misleading, just as "contact cytolysis" and "surface lysosomes" may be false leads in connection with the pathogenicity of $E$. histolytica (Griffin, 1972). The clear halo that often surrounds amoebae in brain tissue or cell cultures (Maitra et al., 1974, 1976; Visvesvara and Callaway, 1974). could be due to local engulfment of host-cell cytoplasm, as was indicated by Brown (1978). Cursons et al. (1978) demonstrated phospholipases in filtrates from cultures supporting high concentrations of $N$. fowleri trophozoites, but the production of these enzymes may not be relevant to the pathogenicity of the organism. According to Fulton (1970), the process of digestion within food vacuoles of Naegleria trophozoites culminates in the expulsion of residual debris by a form of reverse phagocy- 
tosis. It seems likely that digestive enzymes remaining in the vacuoles would be expelled at the same time. Thus, enzymes such as phospholipases that accumulate in Naegleria culture fluids (Cursons et al., 1978) may simply represent products of excretion and hence constitute the final rather than an initial stage of endocytosis. If this interpretation is correct, it follows that enzyme excretion could well be a characteristic of amoebae in general, and it may be premature to associate such enzymes with virulence in the absence of direct, supporting evidence. Significantly, Cursons et al. (1978) also found phospholipases, albeit in smaller amounts, in filtrates from cultures of non-pathogenic amoebae.

Neal (1971) has encouraged the use of cell-culture models in studies of the pathogenicity of E. histolytica. The present findings show the merit of such studies with $N$. fowleri, although it is appreciated that pathogenic organisms often behave abnormally in vitro, and observations may not be relevant to events that take place in the animal host (Smith, 1972). Nevertheless, it seems possible that the in-vitro cytopathogenicity of $N$. fowleri is an alternative expression, at the cellular level, of invasiveness in the whole animal, both phenomena being ultimately related to the feeding activity of trophozoites.

\section{SUMMARY}

The destruction of secondary mouse-embryo (ME) cells by Naegleria fowleri was studied by indirect immunofluorescence with ME-cell antiserum as a specific label to trace the fate of mammalian-cell cytoplasm. The appearance of naegleria-induced cytopathic effect in the cultures coincided with the accumulation of discrete particles containing granules of ME-cell antigen within the cytoplasm of amoebae, suggesting that the organisms ingested host-cell material. In cultures containing cytochalasin B, a non-lethal inhibitor of phagocytosis by $N$. fowleri trophozoites failed to acquire any granular fluorescence and were not cytopathogenic. The engulfment of mammalian-cell cytoplasm by the organisms was confirmed when thin sections of naegleriainfected ME-cell cultures were examined by electron microscopy. Amoebae were seen in the process of detaching portions of cytoplasm from whole ME cells by means of distinctive ingesting pseudopodia, and fragments of mammalian-cell cytoplasm were identified within the food vacuoles of trophozoites. There was no evidence for cytotoxic disruption of ME cells before or during engulfment of these fragments. It is concluded that $N$. fowleri trophozoites attack and destroy cultured ME cells by a phagocytosis-like mechanism alone, without the aid of any amoeba-associated cytotoxic or cytolytic agents. The possible significance of these findings with respect to the in-vivo pathocity of $N$. fowleri is discussed.

\section{REFERENCES}

Allison, A. C., Davies, P. AND De Petris, S. 1971. Role of contractile microfilaments in macrophage movement and endocytosis. Nature, New Biol., 232153. 
AxLINE, S. G. AND Reaven, E. 1972. In vitro inhibition of phagocytosis and disruption of microfilaments by cytochalasin B. J. clin. Invest., 51, 6a.

Bessis, M. 1970. Cell death. Triangle, 9, 191.

Brown, T. 1978. Observations by light microscopy on the cytopathogenicity of Naegleria fowleri in mouse embryo-cell cultures. J. med. Microbiol., 11, 249.

BROWN, T. 1979. Inhibition by amoeba-specific antiserum and by cytochalasin B of the cytopathogenicity of Naegleria fowleri in mouse embryo-cell cultures. J. med. Microbiol., 12, 353.

Butt, C. G., BARO, C. AND KNORR, R. W. 1968. Naegleria (sp.) identified in amebic encephalitis. Am. J. clin. Path., 50, 568.

CARTER, R. F. 1972. Primary amoebic meningo-encephalitis. An appraisal of present knowledge. Trans. R. Soc. trop. Med. Hyg., 66, 193 (see discussion p. 209).

ChANG, S. L. 1971. Small, free-living amebas: cultivation, quantitation, identification, classification, pathogenesis, and resistance. Curr. Top. comp. Pathobiol., 1, 201.

Chang, S. L. 1974. Etiological, pathological, epidemiological and diagnostical considerations of primary amoebic meningoencephalitis. C.R.C. crit. Rev. Microbiol., 3, 135.

Culbertson, C. G. 1971. The pathogenicity of soil amebas. A. Rev. Microbiol., 25, 231.

Cursons, R. T. M. AND Brown, T. J. 1978. Use of cell cultures as an indicator of pathogenicity of free-living amoebae. J. clin. Path., 31, 1.

Cursons, R. T. M., Brown, T. J. AND KeYs, E. A. 1978. Virulence of pathogenic free-living amoebae. J. Parasit., 64, 744.

Duma, R. J., Ferrell, H. W., Nelson, E. C. AND Jones, M. M. 1969. Primary amebic meningoencephalitis. New Engl. J. Med., 281, 1315.

Duma, R. J., Rosenblum, W. I., McGehie, R. F., Jones, M. M. and Nelson, E. C. 1971. Primary amoebic meningoencephalitis caused by Naegleria. Two new cases, response to amphotericin B, and a review. Ann. intern. Med., 74, 923.

Eaton, R. D. P., Meerovitch, E. AND Costerton, J. W. 1969. A surface-active lysosome in Entamoeba histolytica. Trans. R. Soc. trop. Med. Hyg., 63, 678.

EAton, R. D. P., MeERovitch, E. AND Costerton, J. W. 1970. The functional morphology of pathogenicity in Entamoeba histolytica. Ann. trop. Med. Parasit., 64, 299.

Fulton, C. 1970. Amebo-flagellates as research partners: the laboratory biology of naegleria and tetramitus. In Methods in cell physiology, 4, edited by D. M. Prescott, New York and London, p. 341.

GrifFIN, J. L. 1972. Human amebic dysentery. Electron microscopy of Entamoeba histolytica contacting, ingesting and digesting inflammatory cells. Am. J. trop. Med. Hyg. 21, 895.

GRIFFIN, J. L. AND JUNIPER, K. 1971. Ultrastructure of Entamoeba histolytica from human amebic dysentery. Archs. Path., 91, 271.

HaRTwig, J. H. AND Stossel, T. P. 1976. Interactions of actin, myosin, and an actin-binding protein of rabbit pulmonary macrophages. III. Effects of cytochalasin B. J. cell Biol., 71, 295.

JARUmilinta, R. AND KRADOlFER, F. 1964. The toxic effect of Entamoeba histolytica on leucocytes. Ann. trop. Med. Parasit., 58, 375.

LASTOVICA, A. J. 1976. Microfilaments in Naegleria fowleri amoebae. Z. ParasitKde, 50, 245.

Lastovica, A. J. AND Dingle A. D. 1971. Superprecipitation of an actomyosin-like complex isolated from Naegleria gruberi amoebae. Expl cell Res., 66, 337.

Maitra, S. C., Krishna Prasad, B. N., Das, S. R. and Agarwala, S. C. 1974. Study of Naegleria aerobia by electron microscopy. Trans. R. Soc. trop. Med. Hyg., 68, 56.

Maitra, S. C., Krishna Prasad, B. N., Agarwala, S. C. AND Das, S. R. 1976. Ultrastructural studies on experimental primary amoebic meningoencephalitis (PAME) of mouse due to Naegleria aerobia and Hartmannella culbertsoni. Int. J. Parasit., 6, 489.

Martinez, A. J., Duma, R. J., Nelson, E. C. AND Moretta, F. L. 1973. Experimental naegleria meningoencephalitis in mice. Penetration of the olfactory mucosal epithelium by naegleria and pathologic changes produced: a light and electron microscope study. Lab. Invest., 29, 121. 
Martinez, A. J., Nelson, E. C., Jones, M. M., Duma, R. J. and Rosenblum, W. I. 1971. Experimental naegleria meningoencephalitis in mice. An electron microscope study. Lab. Invest., 25, 465.

Neal, R. A. 1971. Progress report. Pathogenesis of amoebiasis. Gut, 12, 483.

Newton, B. A. 1972. Protozoal pathogenicity. In Microbial pathogenicity in man and animals. Symposium no. 22 of the Society for General Microbiology, edited by H. Smith and J. H. Pearce, Cambridge, p. 269.

Persijn, J. P. AND SCherfT, J. P. 1965. Sheet mica-a nonadherent carrier for surface culture of cells to be embedded in Epon. Stain technol., 40, 89.

Plagemann, P. G. W., GrafF, J. C. and Wohlhueter, R. M. 1977. Binding of $\left[{ }^{3}\right.$ H] cytochalasin $B$ and its relationship to inhibition of hexose transport in Novikoff rat hepatoma cells. $J$. biol. Chem., 252, 4191.

Pollard, T. D. AND Korn, E. D. 1973a. Acanthamoeba myosin. I. Isolation from Acanthamoeba castellanii of an enzyme similar to muscle myosin. J. biol. Chem., 248, 4682.

POllard, T. D. AND KORN, E. D. 1973b. Acanthamoeba myosin. II. Interaction with actin and with a new cofactor protein required for actin activation of $\mathrm{Mg}^{2+}$ adenosine triphosphatase activity. J. biol. Chem., 248, 4691.

Pollard, T. D., Stafford, W. F. AND Porter, M. E. 1978. Characterization of a second myosin from Acanthamoeba castellanii. J. biol. Chem., 253, 4798.

Pollard, T. D. and Weiring, R. R. 1974. Actin and myosin and cell movement. C.R.C. crit. Rev. Biochem., $2,1$.

ReAven, E., P. AND AXLINe, S. G. 1973. Subplasmalemmal microfilaments and microtubules in resting and phagocytizing cultivated macrophages. J. cell. Biol., 59, 12.

REYNOLDS, E. S. 1963. The use of lead citrate at high $\mathrm{pH}$ as an electron-opaque stain in electron microscopy. J. cell Biol., 17, 208.

SCHUSTER, F. 1963. An electron microscope study of the amoeboflagellate, Naegleria gruberi (Schardinger). I. The amoeboid and flagellate stages. J. Protozool., 10, 297.

Sмiтн, H. 1972. The little-known determinants of microbial pathogenicity. In Microbial pathogenicity in man and animals. Symposium no. 22 of the Society for General Microbiology, edited by $\mathrm{H}$. Smith and J. H. Pearce, Cambridge, p. 1.

Stossel, T. P. 1974a. Phagocytosis; I. New Engl. J. Med., $290,717$.

Stossel, T. P. 1974b. Phagocytosis; II. New Engl. J. Med., $290,774$.

Visvesvara, G. S. AND Callaway, C. S. 1974. Light and electron microscopic observations on the pathogenesis of Naegleria fowleri in mouse brain and tissue culture. J. Protozool., 21, 239.

WAGNER, P. 1978. What is a myosin? : Acanthamoeba revisited. Nature, Lond., $274,846$.

Weiring, R. R. AND Korn, E. D. 1971. Acanthamoeba actin. Isolation and properties. Biochemistry, N.Y., 10, 590.

Wessells, N. K., Spooner, B. S., Ash, J. F., Bradley, M. O., Luduena, M. A., Taylor, E. L., WrenN, J. T. AND YamadA, K. M. 1971. Microfilaments in cellular and developmental processes. Science, N.Y. 171, 135.

WeStPHAL, A., MiChel, R. AND MÜHLPFORDT, H. 1972. Elektronenmikroskopische Befunde bei der Phagozytose von Crithidia sp. durch Entamoeba histolytica. Z. Tropenmed. Parasit. 23, 117. 